\title{
Using evidence-based debriefing to combat moral distress in critical care nurses: A pilot project
}

\author{
Nicole M. Fontenot ${ }^{* 1}$, Krista A. White ${ }^{2}$ \\ ${ }^{1}$ Center for Nursing Research, Education, and Practice, Houston Methodist Hospital, Houston, TX, USA \\ ${ }^{2}$ Departments of Advanced \& Professional Nursing Practice, School of Nursing \& Health Studies, Georgetown University, \\ Washington DC, USA
}

Received: September 27, 2018

Accepted: December 16, 2018 Online Published: August 13, 2019

DOI: $10.5430 /$ jnep.v9n12p1

URL: https://doi.org/10.5430/jnep.v9n12p1

\begin{abstract}
Objective: Moral distress (MD) is a problem for nurses that may cause despair or disempowerment. MD can have consequences like dissatisfaction or resignation from the nursing profession. Techniques such as evidence-based debriefing may help nurses with MD. Creating opportunities for critical care nurses to debrief about their MD might equip them with the tools needed to overcome it. Measuring MD by using the Moral Distress Thermometer (MDT) could provide insight into how debriefings help nurses. The purpose of this pilot project was to examine the impact of evidence-based debriefing sessions on critical care nurses' sense of MD.

Methods: This pilot project used a quasi-experimental, one-group, before-during-after design. Critical care nurses $(\mathrm{N}=21)$ were recruited from one unit at a large academic medical center. Four debriefing sessions were held every 2 weeks. Participants completed the MDT 2 weeks before the first session, at the end of each session they attended, and 1 month after the debriefing sessions.

Results: In the pilot project, participants felt that debriefing was helpful by increasing their self-awareness, giving them time to commune with colleagues, and encouraging them to improve self-care habits; however, MDT scores did not change significantly when comparing pre with post intervention scores $(t(12)=0.78, p=.450)$.

Conclusions: The use of debriefing may help nurses gain self-awareness of MD and it may offer nurses strategies to build moral resilience.
\end{abstract}

Key Words: Moral distress, Moral resilience, Critical care nursing, Debriefing, Self-awareness

\section{INTRODUCTION}

Most nurses and health care leaders would agree that nursing is a stressful career. The complexity of patients in the 21 st century often contributes to this stress. ${ }^{[1]}$ Moral distress, defined as "painful feelings and/or the physiological disequilibrium that occurs when nurses are conscious of the morally appropriate action a situation requires, but cannot carry out that action because of... obstacles"[2] is just one of the stressors nurses face in their day-to-day lives and can be crippling. When a nurse acts contrary to his or her moral and professional judgment, moral distress can develop. ${ }^{[3]}$ The issues associated with moral distress are particularly prevalent and important in the critical care environment.

First identified by Jameton, ${ }^{[4]}$ moral distress has been studied in nurses for decades. Considerable work has been done to

\footnotetext{
*Correspondence: Nicole M. Fontenot; Email: nfontenot@houstonmethodist.org; Address: Center for Nursing Research, Education, and Practice, Houston Methodist Hospital, Houston, TX, USA. 
define and describe moral distress and the resulting helplessness, despair, and disempowerment that results from it. ${ }^{[5]}$ However, despite the wealth of information about moral distress and strategies to combat its effects, the incidence of moral distress has remained relatively constant over the past 30 years. ${ }^{[6,7]}$ In addition, the health care system is becoming even more complex and patients' health issues are becoming increasingly challenging to manage. These complexities will only intensify the risk for nurses to develop moral distress.

One of the most complex health care settings is critical care, ${ }^{[8]}$ where patients face life-threatening conditions and are often unable to communicate with the health care team for various reasons. This creates a high-pressure environment that is rife with morally complex situations for nurses, patients, and their families. Additionally, nurses who work in the critical care environment are exposed to difficult physical labor, long work hours, and demanding interpersonal interactions. ${ }^{[9]}$ When morally distressing situations arise, piled atop various other stressors in critical care, nurses can become overwhelmed. While many aspects of critical care nursing could contribute to moral distress, often nurses feel morally distressed when providing end-of-life care or when care becomes futile. Moral distress may also develop when there are conflicting opinions among the health care team or when there is a lack of collaboration among the members of the team. ${ }^{[10]}$ If left unchecked, moral distress can build over time, resulting in disempowerment, burnout, or resignation. ${ }^{[5]}$ Effective interventions to reduce moral distress in critical care nurses need to be explored.

Moral distress can have multiple implications on nursing practice and the delivery of health care, including nurses experiencing moral suffering and burnout, providing inadequate nursing care, failing to advocate for the patient's needs due to moral conflict and perceived stress, and increasing turnover rates. These in turn contribute to decreased quality of care and decreased patient satisfaction. ${ }^{[3]}$ When nurses experience moral distress continually or repeatedly, a longterm consequence, called moral residue, may develop. ${ }^{[1]}$ As each new experience of moral distress occurs, the level of moral distress does not return to baseline but in fact leaves behind residue so that over time this compounding effect crescendos and increases the risk for burnout, resignation, and dissatisfaction with the nursing profession. ${ }^{[12]}$

However, more recently nursing and ethical theorists have identified that some health care providers are more adept at dealing with moral distress than others. It is theorized that this is because some health care workers have developed a sense of resilience around their moral distress. For critical care nurses, developing this moral resilience could be a way to combat the effects of moral distress and the resulting helplessness, burnout, and resignation. Structured evidence-based debriefing as an intervention may be a means to mitigate moral distress in critical care nurses and help move them toward moral resilience.

\section{BACKGROUND}

Although information related to moral distress is replete in the literature, literature related to moral residue is sparse. Further, theoretical evidence exists related to moral resilience and how one might work to achieve it. This section of the article explicates important concepts of moral distress, moral residue, and moral resilience. Additionally, the concept of evidence-based debriefing is introduced as an intervention used with nurses.

\subsection{Moral distress}

Since first identified in the 1980s, much attention has been paid to the effects of moral distress on nurses. Initially, moral distress was identified among critical care nurses; more recently, studies have shown that moral distress is present in most nursing specialties as well as in most types of health care providers. ${ }^{[13,14]}$ This may be related to the types of relationships and bonds that health care providers form with their patients. ${ }^{[14]}$ Bruce et al. ${ }^{[15]}$ found that critical care nurses often experience feelings of disempowerment when facing ethical or moral situations. Karanikola et al. ${ }^{[10]}$ similarly found that critical care nurses in Italy experienced more moral distress when they encountered a lack of autonomy, poor nurse-physician collaboration, and unhealthy work environments.

\subsection{Moral resilience}

Moral resilience is "the capacity of an individual to sustain or restore their integrity in response to moral complexity, confusion, distress, or setbacks." ${ }^{[5]}$ Moral resilience can develop through self-awareness, fostering connections with peers, discussing morally distressing situations, and developing ethical competency. ${ }^{[5,12]}$

Empirical evidence confirms moral distress does exist and various factors contribute to it. Equipping nurses to handle morally distressing situations may help them build moral resilience. The term moral resilience has existed in the nursing literature only since 2013. ${ }^{[5,16]}$ No published studies were found that specifically examined moral resilience and no research instruments exist that measure it. ${ }^{[17]}$ Existing literature on moral resilience is primarily expert opinion and theoretical frameworks. Elemental to building moral resilience is the ability of nurses to become self-aware of their own moral distress, to understand that others likely experience similar 
feelings, and to develop ethical competence.

Several experts have described theoretically how to foster moral resilience in nurses. Further, these experts described strategies for building moral resilience. ${ }^{[1,5,12]}$ First, nurses must develop self-awareness of their moral distress. Since each individual nurse might develop moral distress differently, being aware of what triggers their moral distress is key to understanding it and building resilience to it. To develop self-awareness, experts recommended engaging in dialogue about moral distress as a means of developing selfawareness. ${ }^{[12,18]}$

Another key method for developing moral resilience is to create opportunities for nurses to connect with other nurses who experience similar situations. Lachman ${ }^{[12]}$ and Rushton et al. ${ }^{[1]}$ discussed that bringing nurses together and allowing them to see they are not alone in their distress helps to foster a deeper understanding of themselves and the environment in which they work. Furthermore, bringing nurses together to discuss their distress, feelings, and concerns allows them to learn coping mechanisms from one another.

Last, nurses can develop moral resilience through the development of ethical competency. ${ }^{[1,5]}$ One has ethical competency when they consistently live out their ethical beliefs, is sensitive to the moral and ethical complexities they encounter in their daily lives, can reflect upon the moral and ethical makeup of their enviornment, and act as a strong moral agent. ${ }^{[5]}$ Essential to becoming ethically competent is learning from difficult or distressing experiences and enacting action plans for handling similar situations in the future.

\subsection{Debriefing}

Reduction of moral distress may diminish the long-term effects of moral residue. ${ }^{[1]}$ Discussing strategies to overcome moral distress may be useful to build moral resilience. ${ }^{[18]}$ Moral resilience is built by: (1) developing self-awareness, (2) fostering connections with peers, (3) becoming ethically competent, and (4) creating action plans for how to handle morally distressing situations in the future. ${ }^{[1,5,12,16]}$ The development of structured evidence-based debriefing sessions, constructed around the principles of building moral resilience, could help to minimize the effects of moral distress and moral residue.

Debriefing is the practice of reviewing an event or phenomenon and discussing what happened, how it affected those involved, and whether lessons were learned. ${ }^{[19]}$ When done correctly, it can be a safe place for participants to discuss their experiences and feelings, similar to counseling. It has been used to review crises for persons who experience natural disasters or traumatic events. ${ }^{[20]}$ Debriefing is also

Published by Sciedu Press used in various educational disciplines as a teaching or learning tool, such as after simulation activities. ${ }^{[21]}$ Debriefing can be a useful tool for many professions in health care that can be done independently, one-on-one, or as a group.

Using debriefing in the critical care environment may be a useful tool to address moral distress. Rogers et al. ${ }^{[22]}$ found that education about moral agency and debriefing increased nurses' comfort level when caring for dying infants. Santiago and $\mathrm{Abdool}^{[23]}$ found that when creating opportunities for nurses to debrief after morally distressing clinical situations, the nurses verbalized that the debriefing helped to improve their ability to handle these situations. Vaclavik et al. ${ }^{[2]}$ found that debriefing, as part of a mindfulness program, helped to reduce oncology nurses' sense of moral distress. Debriefing allows the health care providers to process the experiences that caused their moral distress.

The American Association of Critical Care Nurses (AACN) developed the 4As of Moral Distress to address moral distress in critical care nurses. ${ }^{[2]}$ The 4As of Moral Distress are composed of distinct components. Ask is the first component of the model in which nurses ask themselves if they are experiencing moral distress. Affirm is the second component, where nurses affirm that their feelings of moral distress are legitimate and valid, and they commit to addressing these feelings. Assess is the third component of the AACN's model, during which nurses evaluate the effect moral distress is having on their professional and personal lives. Act is the fourth and final component of the 4As model. Nurses make a commitment to act in a way that preserves their moral integrity and improves their mental and emotional health. This model, long used by AACN in their work on healthy work environments, could be used to inform the moral distress debriefing process in the critical care environment. Thus, the AACN 4As model was used as a guide to develop the evidence-based debriefing sessions for this pilot project.

\subsection{Purpose}

Current literature validates that moral distress exists in various settings in health care. ${ }^{[13,14]}$ Critical care nurses are considerably vulnerable to its effect because of the difficult and morally complex situations they encounter daily. ${ }^{[8]}$ If left unchecked, moral distress can crescendo into moral residue. Once moral residue develops, nurses become increasingly disengaged and disempowered. ${ }^{[12]}$ However, there is hope for nurses with moral distress. Moral resilience is an emerging concept that describes how nurses can overcome their moral distress by becoming self-aware, communing with their peers, practicing moral agency, and fostering selfcare. ${ }^{[5]}$ What is clearly absent from the literature is evidence about interventions that facilitate reducing moral distress and 
enhancing moral resilience.

Considering the extent to which moral distress affects nurses, health care leaders need to create processes to minimize morally distressing situations and provide opportunities to adequately address moral distress. Creating opportunities for critical care nurses to debrief their moral distress may help nurses feel better about those situations and equip them with the tools needed to build moral resilience. Therefore, the purpose of this pilot project was to determine the feasibility of using evidence-based debriefing sessions for critical care nurses to reduce their self-reported level of moral distress. The pilot project had 3 secondary aims: (1) examine whether a correlation exists between the number of sessions attended and the amount of change in nurses' self-reported level of moral distress, (2) assess whether changes in self-reported moral distress are sustainable after a 4-week washout period with no debriefing, and (3) determine whether debriefing sessions helped participants create strategies to reduce their moral distress.

\section{MeTHODS}

\subsection{Design}

This pilot project used a quasi-experimental, one-group, before-during-after design. The independent variable was the evidence-based debriefing sessions held on 4 days over a period of 10 weeks. The dependent variable was the selfreported level of moral distress in medical intensive care unit (MICU) nurses as measured by the Moral Distress Thermometer (MDT) score. A 4-week washout period was intentionally included in the design of the study to examine whether changes in MDT scores were sustainable without debriefing.

\subsection{Setting and sample}

Participants were registered nurses (RNs) who worked in a 23-bed MICU at a large quaternary care, Magnet $($ designated facility in the southwest region of the United States. Inclusion criteria were as follows: the nurses must (1) be employed as a nurse on the MICU at the practice facility; (2) be at least 18 years of age; (3) work full-time, part-time, or per diem; (4) work any shift; and (5) function as a staff nurse, charge nurse, or nurse manager. All nurses included in the study were required to have direct patient contact; 87 MICU nurses met the inclusion criteria. Exclusion criteria were as follows: nurse residents who had been in nursing practice less than 6 months. The nurse residents participate in debriefing with their resident cohorts as part of their nurse residency program. Therefore, nurse residents were not included in the study because of the challenges of determining whether changes in moral distress were a result of residency programming or the evidence-based debriefing intervention introduced in the study. The study was a pilot project; thus, no power analysis was conducted to determine sample size. It was anticipated that approximately $25 \%$ of the MICU nurses would participate.

\subsection{Ethical considerations}

Institutional review board expedited approval was obtained from Georgetown University and the project site before implementation of the study. Written informed consent was obtained from all participants before the start of the study. The principal investigator was employed as a Clinical Nurse Specialist for the MICU. As such, to avoid any perception of coercion, a decision was intentionally made that the principal investigator would not moderate any debriefing sessions.

Debriefing sessions had the potential to prompt discussion of difficult topics that were emotionally charged. Some of these emotions could be addressed during the debriefing session by the debriefing moderator. If, however, topics were discussed that caused emotional strife beyond the scope of the debriefing, or if participants found themselves distressed after the session, contact information for the employee wellness center at the project site was available and appointments could be made at the participant's convenience.

\subsection{Instrumentation}

Two research instruments were used in this pilot study, the MDT and a brief demographic questionnaire. Demographic characteristics collected from participants included gender, years of experience in nursing, years of experience in critical care, notation of prior education about moral distress, and current healthy coping mechanisms. During the final point of data collection, 2 additional open-ended questions were asked. These questions allowed participants to provide feedback about how they believed the evidence-based debriefings impacted them.

The MDT is an established, validated tool that measures moral distress, experienced in real time. ${ }^{[25]}$ The MDT was designed to measure "acute" moral distress, which the creators defined as being experienced at any point the prior 2 weeks. The creators designed the scale to be utilized repeatedly and no more frequently than every 2 weeks. ${ }^{[25]}$ Since the intent of this pilot project was to capture moral distress in real time, around real-world patient experiences, and to measure changes in moral distress after participation in the debriefing sessions, the MDT tool was appropriate. The MDT is a 1-item instrument that uses a scale of from 0 to 10 , with 0 being no moral distress and 10 being the worst possible moral distress and produces interval-level data. ${ }^{[25]}$ Completion is simple and takes about 1 minute. 


\subsection{Implementation}

\subsubsection{Recruitment and baseline measure}

The nursing leadership in the MICU assisted with recruitment of participants. The MICU nurses were recruited through email notifications, flyers posted around the units, and announcements during daily safety huddles. Recruitment started 1 month before the evidence-based debriefing sessions began.

Pre-surveys and consent forms were distributed to the MICU nursing staff 2 weeks before the first debriefing session by placing the surveys and consent forms in their unit mailbox.
A locked box was conveniently placed next to the mailboxes for staff to return the surveys and consent forms. Nurses were asked to complete the pre-survey within 1 week. At daily safety huddles, nurse managers reminded the nurses of the deadline to complete the pre-survey. They also emailed reminders midweek

\subsubsection{Evidence-based debriefing intervention}

Debriefing sessions were intentionally designed on the basis of the AACN's 4As of Moral Distress. ${ }^{[2]}$ Table 1 illustrates the lesson plan used for the evidence-based debriefing sessions as it related to each of the 4As in the model.

Table 1. Evidence-Based Debriefing Session Lesson Plan

\begin{tabular}{|c|c|}
\hline Topic & Minutes \\
\hline $\begin{array}{l}\text { Introduction: } \\
\quad \text { - Purpose of the session and discuss ground rules for the session }\end{array}$ & 2 minutes \\
\hline $\begin{array}{l}\text { Ask: Goal: Become aware of your own feelings of moral distress. } \\
\text { - Define Moral Distress } \\
\text { - } \quad \text { Do you feel moral distress? }\end{array}$ & 3 minutes \\
\hline $\begin{array}{l}\text { Affirm: Goal: Make a commitment to address your moral distress } \\
\begin{array}{l}\text { - } \\
\text { - }\end{array} \text { Commit to taking care of yourself } \\
\text { - } \quad \text { Validate your feelings }\end{array}$ & 3 minutes \\
\hline $\begin{array}{l}\text { Assess: Goal: Understand the impact of moral distress } \\
\text { - What contributes to your feelings of moral distress? } \\
\text { - What helps you feel better? }\end{array}$ & 7 minutes \\
\hline $\begin{array}{c}\text { Act: Goal: Have a plan to help you preserve your moral integrity } \\
\text { - Set personal and professional goals for taking action } \\
\text { - What are strategies you can use to implement your action plan? } \\
\text { - What can lead to setbacks? How can you avoid these? }\end{array}$ & 10 minutes \\
\hline $\begin{array}{l}\text { Conclusion } \\
\text { - Conclude what was discussed } \\
\text { - Affirm the participants' plans } \\
\text { - Distribute the survey tool—should take }<3 \text { minutes to complete }\end{array}$ & 5 minutes \\
\hline
\end{tabular}

Each session was moderated by a social worker trained in group therapy and in moral distress. The lesson plan and time schedule were reviewed and approved by the nursing director on the unit before implementation.

Debriefing sessions were open to all MICU nurses and were held 30 minutes before change of shift in the evening. Scheduling was completed in this fashion to afford both day and night shift nurses the opportunity to attend and to avoid disruption of patient care. Partial participation was allowed. Nurses were not required to preregister or to commit to attending all sessions.

Debriefing sessions were held 4 times over the course of 10 weeks; one session every 2 weeks. This time frame was chosen because the MDT was designed to be used no more frequently than every 2 weeks. ${ }^{[25]}$ There was an unexpected delay of 2 weeks between the third and fourth debriefing due to a natural disaster in the region.

\subsubsection{Washout and final measurement}

After the last of the 4 debriefing sessions, no debriefing sessions were held for 4 weeks. At the end of this 4 -week washout period, post-surveys were distributed to eligible nursing staff, using the same method of distribution as for the pre-survey. Returned surveys were handled in the same manner as described above.

\subsection{Data analysis}

All statistical analyses were completed by a biostatistician using IBM's Statistical Package for the Social Sciences (SPSS), version 24. ${ }^{[26]}$ Descriptive statistics were used to examine participant demographic characteristics. We anticipated us- 
ing repeated-measures analysis of variance (RM-ANOVA) to analyze the change in MDT scores at each data collection point and to determine if change was sustained after the 4-week washout period. ${ }^{[27]}$ Due to the allowance of partial participation, the sample size at any given data point was smaller than anticipated, thus, a paired-sample-t-test was used to compare mean pre- and post- scores. Pearson's product-moment correlation coefficient was used to examine relationships between the number of sessions attended and the post-MDT scores. ${ }^{[27]}$ A $p$ value of $<.10$ (due to small sample size for a pilot project) was considered statistically significant.

Thematic analysis was conducted on the 2 open-ended questions on the post-survey. The 2 open-ended questions were, "Since participating in the debriefing sessions, what personal action plans have you created to decrease your moral distress?" and "If the debriefing sessions helped you with your moral distress, please describe how." All written-in answers were transposed into an electronic database and evaluated for themes and key words. These themes were then aggregated and categorized.

\section{Results}

\subsection{Attendance}

Eighty-seven nurses were eligible for participation in this pilot project and 21 participated in some aspect of the project. Thus, the participation rate was $24 \%$. The project was de- signed so that eligible nurses could participate at any point in the study. Nurses were not required to commit to attendance at every session or to complete every survey, nor were nurses excluded if they had not completed the pre-survey and then subsequently participated in the debriefing sessions. The pilot was designed this way to maximize participation because nurses on the unit have variable schedules; hence, attendance at all debriefing sessions could not be guaranteed. Mandating full participation in the study may have further reduced the sample size. Additionally, debriefing sessions were held during work hours and near change of shift to foster participation. In light of variable schedules and the allowance for partial participation, the total number of participants $(\mathrm{N}=21)$ is higher than the number of participants who completed both pre- and post-surveys $(n=13)$. Figure 1 explains the attendance rates at each evidence-based debriefing session. The variable nature of the participation led to variations in the data. For example, one participant could have completed the pre-survey and one debriefing session, another participant could have completed the pre-survey and attended all debriefings, and a third participant could have only completed the pre- and-post-surveys. It is important to note that of the 16 nurses who completed the post-survey, 13 attended at least one debriefing session. For clarity and comprehensiveness, each results table discussed hereafter will display the results for all participants $(\mathrm{N}=21)$ as well as for only those who completed both a pre- and a post-survey $(n=13)$.

\begin{tabular}{|c|c|}
\hline Pre-Survey & $\begin{array}{l}-2 \text { Weeks prior to beginning debriefings } \\
\cdot n=17\end{array}$ \\
\hline D1 & $\begin{array}{l}\cdot \text { MDT given after debreifing session } \\
\cdot \mathrm{n}=5\end{array}$ \\
\hline D2 & $\begin{array}{l}\cdot \text { MDT given after debriefing session } \\
\cdot \mathrm{n}=4\end{array}$ \\
\hline D3 & $\begin{array}{l}\cdot \text { MDT given after debriefing session } \\
n=3\end{array}$ \\
\hline D4 & $\begin{array}{l}\cdot \text { MDT given after debriefing session } \\
\cdot \mathrm{n}=3\end{array}$ \\
\hline Post-Survey & $\begin{array}{l}\cdot 4 \text { weeks after debriefing concluded } \\
\cdot n=16\end{array}$ \\
\hline
\end{tabular}

Figure 1. Participation at each data collection point

\subsection{Sample}

\subsubsection{Demographics}

Twenty-one nurses participated in this pilot project. Figure 2 details the demographics of the participants. Seventy-one percent of the participants were female and $28.6 \%$ were male. Three ethnicities were self-reported by the participants: $66 \%$ white, $19 \%$ Hispanic, and $14.3 \%$ Asian.

Although the mean number of years of experience in nursing was 7.93 years, the nurses' experience ranged from 1 to 27 6 years. Similarly, the mean number of years in critical care was 6.36 years, with a range of from 1 to 20 years. The years of experience in both nursing and critical care were highly positively skewed. Eighty percent of the nurses had less than 5 years of nursing experience while the remaining $20 \%$ of participants had over 20 years of experience as a nurse. The more seasoned nurses on the unit pulled the mean to the right. As anticipated, most participants in the study were nurses with fewer than 5 years of experience.

ISSN 1925-4040 E-ISSN 1925-4059 


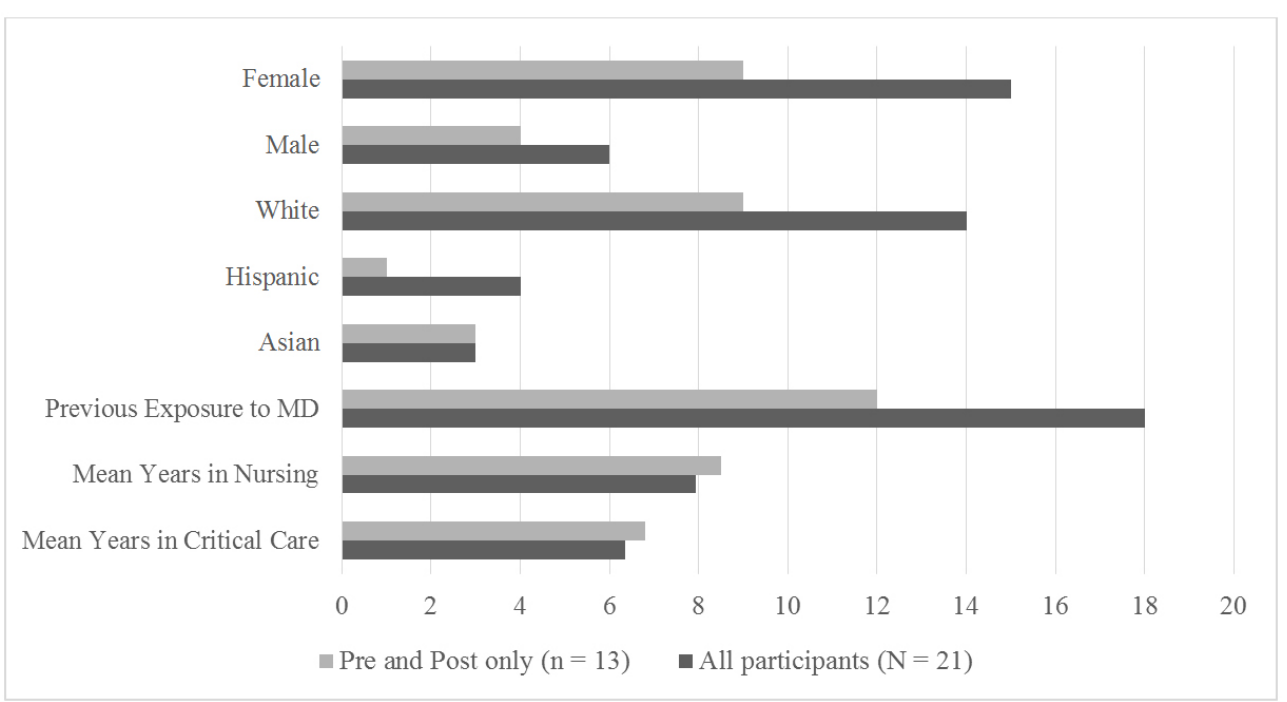

Figure 2. Characteristics of the sample

\subsubsection{Healthy coping}

At each point in the data collection process, participants identified their current healthy coping techniques. Table 2 describes the healthy coping techniques used by the study participants. The techniques most frequently used were spending time with family and friends, exercise, watching televi- sion, and participating in hobbies. Two participants identified "other" techniques, which included being alone and spending time with their pet. No participant indicated that he or she had zero healthy coping techniques, nor did any participant list any unhealthy techniques.

Table 2. Healthy coping techniques used by participants

\begin{tabular}{lll}
\hline & All Participants (N = 21) & Pre and Post only (n = 13) \\
\cline { 2 - 3 } & No. $\mathbf{( \% )}$ & No. $(\%)$ \\
\hline Exercise & $15(71.4)$ & $9(69.2)$ \\
Hobbies & $13(61.9)$ & $8(61.5)$ \\
Yoga & $2(9.5)$ & $2(15.4)$ \\
Meditation & $3(14.3)$ & $2(15.4)$ \\
Prayer & $9(42.9)$ & $6(46.2)$ \\
Social Media & $5(23.8)$ & $4(30.8)$ \\
Watching TV & $15(71.4)$ & $8(61.5)$ \\
Browsing the Internet & $10(47.6)$ & $7(53.8)$ \\
Listening to Music & $12(57.1)$ & $8(61.5)$ \\
Spending Time with Family or Friends & $19(90.5)$ & $12(92.3)$ \\
Other & $2(9.5)$ & $1(7.7)$ \\
\hline
\end{tabular}

\subsection{Primary aim findings}

The primary aim of this pilot project was to determine the feasibility that 4 evidence-based debriefing sessions for critical care nurses would reduce their self-reported level of moral distress. We were unable to use RM-ANOVA as planned owing to the small numbers of participants who attended any given debriefing session and the allowance of partial participation. Instead, the pre-survey MDT scores and the post-survey MDT scores for the 13 participants who com- pleted both a pre- and a post-survey were analyzed. Using paired-samples $t$-tests, no significant difference was found between mean pre- and post-survey MDT scores $(t(12)=$ $0.78, p=.450)$.

Table 3 illustrates the descriptive statistics for mean MDT scores at each data collection point through the project. MDT scores range from 0 to 10 , with 0 being no moral distress and 10 being the worst possible moral distress. ${ }^{[25]}$ The mean 
pre-debriefing score, collected 2 weeks before the first debriefing session, revealed the lowest amount of moral distress among participants $(3.12 \pm 2.62)$. Subsequently, the following 3 debriefing sessions saw an incremental rise in mean MDT scores, indicating higher reported levels of MD. Finally, mean MDT scores drifted back toward the pre-debriefing scores for the fourth debriefing session and the post-survey data collection points, indicating lower reported levels of MD. It is important to note there was a 4-week gap between the third and the fourth debriefing session, instead of the usual 2 weeks. This unintended gap was due to a natural disaster that occurred in the region. The possible impact of this disaster is explored in the Discussion.

Table 3. Scores on the Moral Distress Thermometer*

\begin{tabular}{lllll}
\hline & $\mathbf{N}=\mathbf{2 1}$ & Mean (SD) & $\mathbf{n = 1 3}$ & Mean (SD) \\
\hline Pre & 17 & $3.12(2.62)$ & 13 & $3.77(2.62)$ \\
Debrief 1 & 5 & $3.80(2.68)$ & 4 & $4.50(2.52)$ \\
Debrief 2 & 4 & $5.00(2.58)$ & 1 & $8.00(\mathrm{na})$ \\
Debrief 3 & 3 & $5.33(1.16)$ & 2 & $5.00(1.41)$ \\
Debrief 4 & 4 & $3.25(0.50)$ & 4 & $3.25(0.50)$ \\
Post & 16 & $3.31(2.02)$ & 13 & $3.15(2.08)$ \\
\hline
\end{tabular}

* Each participant may not have completed a survey at each data point.

\subsection{Secondary aims findings}

\subsubsection{Correlation between the sessions and moral distress} scores

One secondary aim of this pilot project was to examine whether a correlation existed between the number of sessions attended and the nurses' self-reported level of moral distress at the end of the project. Pearson's product-moment correlation coefficient was used to test this aim. No relationship was found between the number of sessions and post-survey MDT scores among all participants $(r=0.02, p=.937)$. Partial participation was allowed in the study; therefore, the numbers of nurses who attended any given evidence-based debriefing session varied considerably. For instance, one nurse may have attended just one debriefing session while another nurse attended 3 out of 4 debriefing sessions.

\subsubsection{Sustainability over time}

Another secondary aim was to examine whether any reduction in self-reported level of moral distress was sustainable after a period of 4 weeks without evidence-based debriefing sessions. Owing to the small sample size, partial participation, and varied amount of attendance at any given debriefing session, RM-ANOVA was not able to be performed as originally planned. Subsequently, this secondary aim could not be answered.

\subsubsection{Benefits of debriefing}

The final secondary aim for this pilot project was to determine how debriefing sessions impacted the participants' ability to create strategies to reduce their moral distress. Four weeks after the final debriefing session, each participant was asked 2 additional open-ended questions:

- Since participating in the debriefing sessions, what personal action plans have you created to decrease your moral distress?

- If the debriefing sessions helped you with your moral distress, please describe how.

Ninety-three percent of the participants who completed the post-survey (15 of 16 nurses) responded to these questions. The answers to these questions provided insights into how the debriefing sessions helped the participants. All written-in responses were transposed into an electronic database, evaluated for themes and keywords, which were then aggregated and categorized. Table 4 summarizes the responses from the participants. The main themes identified were increasing self-awareness, connecting with colleagues, and fostering self-care habits.

Table 4. Themes from the participants' responses about the impact of debriefing

\begin{tabular}{ll}
\hline Theme & Significant Statements \\
\hline \multirow{2}{*}{ Increase Self-Awareness } & More aware of what causes moral distress \\
& Understand why I feel sad sometimes \\
& Feel less alone \\
Connect with Colleagues & Helped discussing moral distress with those who were in the same situation \\
& Learning what others do to cope helps me cope better \\
& Exercise \\
& Eating healthy foods \\
Foster Self-care Habits & Spending more time with support system \\
& Spending time in nature \\
& Take time off work \\
\hline
\end{tabular}




\section{Discussion}

This small pilot project in one MICU explored changes in critical care nurses' self-reported levels of moral distress before, during, and after four 30-minute debriefing sessions. The findings can help to determine the feasibility of conducting evidence-based debriefing around moral distress in critical care nurses on a larger scale. It is acknowledged that due to patient care commitments and the nurses' availability, participation at each debriefing in our study was small. Interestingly, moral distress scores started relatively low at the beginning of the study (indicating less distress), rose as participants engaged in evidence-based debriefing (indicating more distress), and then fell back toward baseline. Participating in the debriefings may have increased the nurses' self-awareness, allowed them to spend time with their peers, and fostered ways to develop their own self-care. This awareness may assist nurses in building moral resilience and, subsequently, help combat moral distress.

\subsection{Discovering moral distress}

The MDT scores did not change significantly over the course of the study. This could be due in part to the time frame for this project. No empirical evidence exists to indicate how long it takes to change one's moral distress or how long it takes to build moral resilience. These questions remain to be answered with further research. The total time between the pre- and post-surveys was 16 weeks, with each debriefing 2 to 4 weeks apart. The project was intentionally designed in this fashion because the MDT is intended to be used no more frequently than every 2 weeks. ${ }^{[25]}$

Baseline moral distress scores in the MICU nurses in this study were surprising. These MDT scores were lower than anticipated. On the basis of the feedback received from nurse leaders on the unit during the design phase and while conducting a needs assessment, pre-survey scores were anticipated to have been considerably higher. We considered that perhaps participants noted lower levels of MD at baseline because they were not even aware of their own moral distress. Because the first 2 steps of the AACN's 4As of moral distress $^{[2]}$ are Ask and Affirm, the first half of each debriefing session focused on helping the nurses explore their experiences with moral distress. It is surmised that merely asking about MD brought the concept to participants' forethoughts; thus, raising awareness. Leggett et al. ${ }^{[28]}$ similarly found that nurses' moral distress levels rose as more attention was paid to moral distress concepts. Many participants who completed the post-survey commented that they became much more self-aware of their moral distress after participating in the evidence-based debriefing sessions and acknowledging that their feelings were real and related to moral distress.
Responses such as these may partially explain low baseline scores. Before the pilot project, the participants lacked selfawareness or perhaps did not even realize the existence of moral distress.

\subsection{Impact of debriefing}

Findings from our pilot project indicated that the mean MDT score was lowest at the beginning of the study and rose after debriefing sessions 1 through 3 . Although initially surprised and concerned by this result, we subsequently determined that this may be part of the natural course of becoming selfaware and moving toward building resilience. Becoming more self-aware may actually lead to reporting higher MDT scores. Because the first step of AACN's 4As of moral distress is to Ask if you have moral distress, ${ }^{[2]}$ this was a key component of each debriefing. By giving participants time to explore their own moral distress, discuss their distress with colleagues, and acknowledge their feelings, participants likely became more self-aware. This self-awareness might also assist the participants in mitigating the formation of moral residue and halting the crescendo effect. ${ }^{[11]}$ Such improvements in self-awareness and the concomitant rise in MDT scores across the first 3 debriefing sessions is considered a favorable finding of the study.

The project participants' self-awareness seemed to spread beyond the debriefing sessions. Anecdotally, nursing leadership on the unit noted that between sessions, many nurses seemed to be discussing moral distress among themselves, sharing their experiences from the debriefings, and talking about their personal action plans for combatting moral distress. This created a positive energy around the unit, and other nurses who did not participate at the beginning of the project became interested in the pilot project and later joined in. The attention and mental energy being paid to moral distress by the nurses in the MICU may have further contributed to the rise in scores in each of the first 3 debriefing sessions.

One unexpected historical event occurred during the implementation of the pilot project which may have influenced the results. The region where this pilot project was conducted was struck by a devastating natural disaster just before the fourth debriefing session. Many participants in the project were mandated to remain at the hospital for 4 to 5 consecutive days to provide patient care. During this time, nurses were unaware if their families or friends were safe or if their homes and property had been destroyed. Many others who were not at the hospital during the disaster were evacuated or had to relocate into temporary shelters. More than a week passed until the hospital was able to resume normal operations. The last debriefing session was scheduled 1 week after normal operations resumed. By this time, the focus 
on the unit had shifted away from moral distress and from any progress which may have been made over the previous weeks of the pilot. As expected, survivors of the disaster were focusing their attention and mental energy on other stressors: disaster recovery. While they may still have been interested in addressing their own moral distress, this was no longer the focus of study participants in the immediate disaster aftermath, when the fourth debriefing session and post-survey took place. Mean MDT scores for debriefing session 4 and for the post-survey returned to nearly the scores seen at baseline.

During natural disasters, nurses are at risk for facing morally distressing situations. During Hurricane Katrina in 2005, the situation necessitated that nurses make life-or-death decisions about which patients to evacuate from the hospitals. Furthermore, some reports indicated scenarios where health care providers administered medications to hasten death for already dying patients who could not be evacuated. ${ }^{[29]}$ Largely, this was due to the hospitals flooding, losing water and electricity, and depleting medication supplies. Many facilities had limited capacity to evacuate critically ill patients. Fortunately, the hospital where this pilot project was conducted had allocated vast fiscal resources, over the past decade, to prepare its infrastructure for such disasters (T. Riley, personal communication, September 8, 2017). While some outpatient offices flooded, electricity was never lost, no inpatient unit required closure during the disaster, and no patients required evacuation. In fact, many surrounding hospitals evacuated their patients to this facility. The hurricane itself likely caused moral distress for the nurses, knowing that there were likely patients who could not reach the hospital and get the treatment they needed during the disaster. Despite the disaster, MDT scores drifted down to baseline in the time after. It may be reasonable that the nurses' attention and mental energy were focused on other stressors, patient care, and patient safety instead of their own sense of moral distress, thus reducing their MDT scores.

\subsection{Moving toward resilience}

Self-awareness is the first step toward building moral resilience. ${ }^{[5]}$ The debriefing sessions created a forum that allowed participants to explore their feelings of moral distress and created self-awareness. Self-awareness encompasses the first 2 As of AACN's 4As of Moral Distress: Ask and Affirm. ${ }^{[2]}$ Findings from this study are consistent with literature related to the importance building resilience by communing with others and exploring feelings. ${ }^{[1,5,12]}$ Many participants articulated this in the comments placed on the post-survey.

One participant wrote: "[The debriefing sessions] helped me vent my feelings. I have more outlets to combat moral dis- tress - to be physically healthy and mentally prepared every time [I] go to work, and to find time to rejuvenate my mind and body when I am experiencing distress."

Another participant noted, "just talking about things" helped them become more aware. This self-awareness helps nurses understand their triggers for moral distress, so they can cope more effectively.

Another important aspect of building moral resilience is giving nurses time to empathize with their peers. ${ }^{[1,12]}$ By giving them time to discuss their feelings with their colleagues and understand that they are not alone, nurses can become more resilient to their moral distress. This opportunity occurred during all parts of the debriefing sessions, but the participants particularly focused on this when they discussed the Assess aspect of the 4As. During Assess, they talked about how their moral distress affected their work and personal lives. During Assess, participants were able to discuss with their peers how their shared experiences impacted them individually. Findings from our pilot are consistent with existing literature about time and empathy. ${ }^{[15]}$ Many of the participants in our study expressed that they benefited from spending time discussing their moral distress with their colleagues during the debriefing sessions.

One participant wrote: "Helped me to realize that we all go through moral distress, that I am not alone. Moreover, there are people with who[m] I can go to as resources to express when I feel distress." Another participant wrote: "I'm not alone! My co-workers' experience is very similar to mine."

By spending time with their colleagues discussing their moral distress, nurses realize they are not the only ones who experience these feelings. Nursing leaders who create protected time and space to allow such discussions can help facilitate growth of moral resilience in their staff.

Another technique for building moral resilience is to foster self-care. ${ }^{[18]}$ The last "A" in the AACN's 4As of moral distress is Act. ${ }^{[2]}$ In the last few minutes of each debriefing, the moderator asked the participants to create an action plan for themselves that they would implement after the debriefing. These action plans included many self-care techniques, such as exercise, yoga, healthy eating, spending time in nature, spending time with their social support systems, prayer, and meditation. On the post-survey, $100 \%$ of the participants noted that they were more focused on their self-care since attending the debriefings. Encouraging self-care is crucial for developing moral resilience. ${ }^{[18]}$

\subsection{Limitations}

This small pilot project had several limitations. First, it was conducted on a single unit at one hospital and convenience 
sampling was used. Second, the numbers of attendees at any given debriefing session were quite small, although overall participation was $24 \%$ of eligible staff. Third, the total study time frame was just 16 weeks. It is currently unclear, according to moral distress experts, how long it takes to change moral distress or build moral resilience. It is possible that this time frame may have been inadequate to truly impact MDT scores as intended. Last and perhaps most dramatically, the implementation and data collection for this pilot project was disrupted and delayed by a natural disaster. Although the project was able to continue after the hospital resumed normal operations, the mood on the unit following the disaster had changed. While it is unclear how outcomes of the project may have differed had a natural disaster not occurred, it is possible that the disaster influenced the pilot project and its outcomes.

\subsection{Implications}

This pilot study has several implications for nursing practice, health care organizations, and nursing education. The primary implication for nursing practice is that the use of an evidence-based debriefing strategy may improve nurses' self-awareness of their moral distress and may help them build moral resilience. Additionally, when nursing leaders allow their staff time away from bedside practice to engage in an exercise such as debriefing, they validate to their staff that they are valued assets. This may improve the nurses' satisfaction and desire to stay with their organization.

Another implication for practice is a potential for improving patient care. It has been shown that patients have worse outcomes when receiving care from nurses with moral distress. ${ }^{[3]}$ Patients benefit from receiving nursing care from nurses without moral distress. Health care organizations that acknowledge that moral distress is a very real issue could support the nursing staff by creating programs to build moral resilience for their staff.

Health care organizations may benefit from routinely using an evidence-based debriefing strategy to combat moral distress. Moral distress is linked to higher turnover rates. ${ }^{[3]}$ By investing time and resources in training moderators to effectively debrief and giving staff time away from patient care to participate in debriefing, organizations may be able to retain their nursing staff. In fact, turnover is often quite high for recently graduated nurses. ${ }^{[30]}$ By focusing on developing moral resilience in graduate nurses, while they are still in their residency, organizations may be able to improve retention rates among nurses. Nurse residency programs cost approximately $\$ 200,000$ to $\$ 400,000$ per year, ${ }^{[31]}$ thus, losing nurse residents after just 12 or 18 months of employment is a financial burden. Allocating resources to help nurses develop moral resilience could equate to eventual cost savings.

Last, this pilot project has implications for nursing education. Teaching moral agency to nursing students may equip them more effectively as they transition into clinical practice. Nursing faculty and nursing students must become aware of the crescendo effects and moral residue that result from repeated exposures of moral distress. ${ }^{[11]}$ Furthermore, teaching nursing students about moral resilience and the use of evidence-based debriefing strategies during their academic program may help students build moral resilience before they begin their professional practice. Preparing them for the moral complexities they will inevitably encounter in practice, teaching them moral agency, and equipping them with tools to build their own moral resilience may help the future generations of nurses overcome moral distress.

\subsection{Recommendations for future research}

Despite small numbers, findings appear to support that debriefing sessions affect nurses' awareness of moral distress and help them create strategies to become morally resilient. Thus, it may be feasible to implement such sessions across the organization where moral distress is most prevalent. Additional research needs to be conducted in the area of moral distress and moral resilience. A longitudinal study, conducted over 1 year or longer, could examine how nurses' self-reported moral distress scores change over time. Further research could be conducted to examine how the use of an intervention such as debriefing impacts nursing staff turnover rates and employee satisfaction scores. Studies could be conducted in settings outside of critical care, such as in acute care or the perioperative environment, as well as at other types of organizations, such as clinics, hospice centers, community hospitals, and public hospitals. Last, research that examines how debriefing affects nurse residents in their first year of practice would also be beneficial.

\section{Conclusion}

Moral distress is a persistent and well-documented problem for nurses. Implementing interventions, such as evidencebased debriefing, may help nurses become more self-aware, help them foster their self-care, and allow them time to commune with their peers. Creating opportunities for nurses to use debriefing may be an effective way to combat moral distress and build moral resilience.

\section{CONFlicts of InTERest Disclosure}

The author declares that there is no conflict of interest statement. 


\section{REFERENCES}

[1] Rushton CH, Caldwell M, Kurtz M. CE: Moral distress: a catalyst in building moral resilience. Am J Nurs. 2016; 116(7): 40-49. PMid:27294668 https ://doi.org/10.1097/01.NAJ.0000484 $933.40476 .5 \mathrm{~b}$

[2] AACN. Moral distress: Position statement [Internet]. American Association of Critical-Care Nurses; c2008 [cited 2016 July 17]. Available from: http://www . aacn .org/WD/Practice/Docs/Moral_ Distress.pdf

[3] Corley MC. Nurse moral distress: a proposed theory and research agenda. Nurs Ethics. 2002; 9(6): 636-650. PMid:12450000 https : //doi.org/10.1191/0969733002ne557oa

[4] Jameton A. Nursing Practice: The Ethical Issues. Upper Saddle River, NJ: Prentice-Hall; 1984.

[5] Rushton $\mathrm{CH}$. Moral resilience: a capacity for navigating moral distress in critical care. AACN Adv Crit Care. 2016; 27(1): 111-119. PMid:26909461 https ://doi.org/10.4037/aacnacc2016275

[6] Musto LC, Rodney PA, Vanderheide R. Toward interventions to address moral distress: navigating structure and agency. Nurs Ethics. 2015; 22(1): 91-102. PMid:24917268 https ://doi .org/10.117 7/0969733014534879

[7] Sauerland J, Marotta K, Peinemann MA, et al. Assessing and addressing moral distress and ethical climate, part 1. Dimens Crit Care Nurs. 2014; 33(4): 234-245. PMid:24895954 https ://doi.org/ 10.1097/DCC. 0000000000000050

[8] Henrich NJ, Dodek PM, Gladstone E, et al. Consequences of moral distress in the intensive care unit: a qualitative study. Am J Crit Care 2017; 26(4): e48-e57. PMid:28668926 https ://doi .org/10.403 $7 /$ ajcc2017786

[9] Raj MAK. Job stress among staff nurses working in critical care units and their socio-demographic correlates: a cross sectional survey. Glo J Crit Care. 2016; 4(12): 334-335.

[10] Karanikola MN, Albarran JW, Drigo E, et al. Moral distress, autonomy and nurse-physician collaboration among intensive care unit nurses in Italy. J Nurs Manag. 2014; 22(4): 472-484. PMid:23489299 https://doi.org/10.1111/jonm. 12046

[11] Epstein EG, Hamric AB. Moral distress, moral residue, and the crescendo effect. J Clin Ethics. 2009; 20(4): 330-342.

[12] Lachman VD. Moral resilience: managing and preventing moral distress and moral residue. Medsurg Nurs. 2016; 25(2): 121-125.

[13] De Villers MJ, DeVon HA. Moral distress and avoidance behavior in nurses working in critical care and noncritical care units. Nurs Ethics. 2013; 20(5): 589-603. PMid:23186938 https://doi.org/10.1 $177 / 0969733012452882$

[14] Houston S, Casanova MA, Leveille M, et al. The intensity and frequency of moral distress among different healthcare disciplines. J Clin Ethics. 2012; 24(2): 98-112.

[15] Bruce CR, Miller SM, Zimmerman JL. A qualitative study exploring moral distress in the ICU team: the importance of unit functionality and intrateam dynamics. Crit Care Med. 2015; 43(4): 823-831. PMid:25525754 https://doi.org/10.1097/CCM.0000000000 000822

[16] Monteverde S. Undergraduate healthcare ethics education, moral resilience, and the role of ethical theories. Nurs Ethics. 2014; 21(4): 385-401. PMid:24311237 https://doi.org/10.1177/096973 3013505308
[17] Young PD, Rushton CH. A concept analysis of moral resilience. Nurs Outlook. 2017; 65(5): 579-587. PMid:28434608 https://doi .or g/10.1016/j.outlook. 2017.03.009

[18] American Nurses Association. A call to action: Exploring moral resilience toward a culture of ethical practice. American Nurses Association; c2017 [cited 2017 Nov 1]. Available from: https://drive.google.com/file/d/OB8C-I-8yxX-Y YWlwNmZ2YUhzTzg/view

[19] Hanna DR, Romana M. Debriefing after a crisis. Nurs Manage. 2007; 38(8): 38-42. https://doi.org/10.1097/01. NUMA.00002861 $90.06433 .0 \mathrm{~b}$

[20] Smith LE, Bernal DR, Schwartz BS, et al. Coping with vicarious trauma in the aftermath of a natural disaster. J Multicult Couns Devel 2014; 42(1): 2-12. https://doi.org/10.1002/j.2161-1912. 2014.00040.x

[21] Garden AL, Le Fevre DM, Waddington HL, et al. Debriefing after simulation-based non-technical skill training in healthcare: a systematic review of the effective practice. Anaesth Intensive Care. 2015; 43(3): 300-308. PMid:25943601 https://doi .org/10.1177/03 $10057 X 1504300303$

[22] Rogers S, Babgi A, Gomez C. Educational interventions in endof-life care: Part 1: an educational intervention responding to the moral distress of NICU nurses provided by an ethics consultation team. Adv Neonatal Care. 2008; 8(1): 56-65. PMid:18300739 https://doi.org/10.1097/01. ANC.0000311017.02005.20

[23] Santiago C, Abdool S. Conversations about challenging end-of-lifecases: ethics debriefing in the medical-surgical intensive care unit. Dynamics. 2011; 22(4): 26-30.

[24] Vaclavik EA, Staffileno BA, Carlson E. Moral distress: using mindfulness-based stress reduction interventions to decrease nurse perceptions of distress. Clin J Oncol Nurs. 2018; 22(3): 326332. PMid:29781473 https://doi.org/10.1188/18.CJON.32 6-332

[25] Wocial L D, Weaver MT. Development and psychometric testing of a new tool for detecting moral distress: the Moral Distress Thermometer. J Adv Nurs. 2013; 69(1): 167-174. PMid:22607094 https : //doi .org/10.1111/j.1365-2648.2012.06036.x

[26] IBM Corporation. Released 2016. IBM SPSS Statistics for Windows, version 24.0. Armonk, NY: IBM Corp.

[27] Sylvia M, Terhaar MF. Clinical Analytics and Data Management for the DNP. New York, NY: Springer Publishing Company; 2014.

[28] Leggett JM, Wasson K, Sinacore JM, et al. A pilot study examining moral distress in nurses working in one United States burn center. J Burn Care Res. 2013 Sep-Oct; 34(5): 521-8. PMid:23884046 https ://doi.org/10.1097/BCR.0b013e31828c7397

[29] Fink S. The deadly choices at memorial [Internet]. The New York Times. 2009 Aug 1 [cited 2017 Nov 17]. Available from: http://www.nytimes.com/2009/08/30/magazine/30 doctors.html?pagewanted=all

[30] Colosi B. 2016 National healthcare retention \& RN staffing report [Internet]. NSI Nursing Solutions, Inc; c2016 [cited 2016 Oct 23]. Available from: http://www.nsinursingsolutions.com/Fi les/assets/library/retention-institute/NationalHea 1thcareRNRetentionReport2016.pdf

[31] Hansen J. Nurse residency programs: a critical part of the future of nursing, part 2. J Nurses Prof Dev. 2013; 29(3): 157-158. PMid:23703278 https://doi.org/10.1097/NND.0b013e3182 91 bea5 